\title{
Efeito de anti-inflamatórios não esteroidais na apoptose de células epidermais lamelares de equinos com laminite
}

\author{
[Effect of nonsteroidal anti-inflammatory drugs on apoptosis of epidermal lamellar \\ cells of equines with laminitis] \\ C.A.P. Gonçalves ${ }^{1}$, P.T.L. Botteon ${ }^{1}$ *, G. E.S. Alves ${ }^{2}$, R.R. Faleiros ${ }^{2}$, \\ F.O. Paes Leme ${ }^{2}$, H.M.F. Mendes ${ }^{2}$, A.C. Vasconcelos ${ }^{3}$ \\ ${ }^{1}$ Aluno de pós-graduação - Universidade Federal Rural do Rio de Janeiro, Seropédica, RJ \\ ${ }^{2}$ Escola de Veterinária - Universidade Federal de Minas Gerais - Belo Horizonte, MG \\ ${ }^{3}$ Instituto de Ciências Biológicas - Universidade Federal de Minas Gerais - Belo Horizonte, MG
}

\section{RESUMO}

O objetivo deste trabalho foi avaliar a influência da administração dos anti-inflamatórios não esteroidais (AINEs) cetoprofeno, fenilbutazona e flunixin meglumine sobre o índice apoptótico de células epiteliais do tecido lamelar de cavalos com laminite induzida por administração de amido. Foram empregados 20 equinos hígidos, divididos em quatro grupos experimentais $(n=5)$ : solução salina, cetoprofeno, fenilbutazona e flunixin meglumine. O tecido lamelar foi coletado por biópsia, fixado e corado pela técnica de TUNEL. À marcação positiva por essa técnica adicionou-se a avaliação morfológica celular para identificação da apoptose. Não houve diferença significativa no índice apoptótico entre os grupos tratados com anti-inflamatórios e o controle $(\mathrm{P}>0,05)$. Os anti-inflamatórios não interferiram sobre o índice apoptótico possivelmente porque foram administrados após a fase prodrômica da laminite e/ou porque não são eficazes em alterar a dinâmica da apoptose. Concluiu-se que a administração de antiinflamatórios não esteroidais após a fase prodrômica da laminite não contribui para uma intervenção no curso da apoptose no tecido lamelar de cavalos com laminite quando comparados ao grupo controle não tratado. Outros estudos, com diferentes períodos de avaliação, são necessários para esclarecer os efeitos dos anti-inflamatórios não esteroidais na fisiopatologia da laminite em equinos, especialmente no que concerne à participação da apoptose.

Palavras-chave: apoptose, equinos, laminite

\begin{abstract}
The aim of this study was to evaluate the influence of the administration of anti-inflammatory drugs (NSAIDs) ketoprofen, phenylbutazone and flunixin meglumine on the apoptotic index of the epithelial cells of lamellar tissue of horses with induced laminitis. 20 healthy horses were employed and underwent induction of laminitis by administration of starch, divided into four groups with induced laminitis $(n=5)$ : saline, ketoprofen, phenylbutazone and flunixin meglumine. The lamellar tissue was collected by biopsy, fixed and stained with the TUNEL technique. All that were stained positive by this technique were added to the cell morphological identification of apoptosis. No significant difference was found in the apoptotic index between the groups treated with anti-inflammatory and controls $(P>0.05)$. It was concluded that the administration of NSAIDs after the prodromal phase of laminitis does not contribute to an intervention in the course of apoptosis in the lamellar tissue of horses with laminitis when compared to the untreated control group. Other studies with different evaluation periods are needed to clarify the effects of anti-inflammatory non-steroidal drugs in the pathophysiology of laminitis in horses, especially regarding the role of apoptosis.
\end{abstract}

Keywords: apoptosis, equine, laminitis

Recebido em 6 de maio de 2012

Aceito em 15 de março de 2013

*Autor para correspondência (corresponding author)

E-mail: pbotteon@ufrrj.br 


\section{INTRODUÇÃO}

A apoptose é um mecanismo de morte celular programada, descrito em 1972 (Kerr et al., 1972), e ocorre segundo a ativação de vias de sinalização específicas que resultam na deleção de células do tecido (Collins et al.,1994; MatuteBello e Martin, 2003). A apoptose é regulada geneticamente e está implicada na embriogênese, na renovação celular dos tecidos adultos, no envelhecimento e em muitas doenças (Renehan et al., 2001; Zhang et al., 2005). A apoptose pode ocorrer naturalmente ou por indução de drogas, radiação, calor e mediadores inflamatórios (Columbano 1995; Renehan et al., 2001). Sua principal característica é que a célula morta é fagocitada por macrófagos ou células vizinhas, sem que ocorra liberação do conteúdo citoplasmático e sem que haja o desencadeamento de um processo inflamatório (Kerr et al., 1972).

Um dos primeiros eventos observados na laminite é a desintegração da membrana basal (MB) das lamelas do casco e a falha da MB em permanecer ligada às células basais das lâminas epidermais secundárias (LES). A ativação de metaloproteinases (MMPs) da MB de forma descontrolada é responsável pela perda e desorganização lamelar da MB (Pollit e Daradka, 1998). Essas enzimas são responsivas ao controle fisiológico de crescimento do casco e podem ser ativadas por meio de mediadores inflamatórios, tais como fator de necrose tumoral alfa (TNF- $\alpha$ ) e citocinas (Black et al., 2006; Belknap, 2009). A apoptose está aumentada em casos de laminite aguda (Souza, 2007) e crônica (Faleiros et al., 2004).

Os AINEs são o pilar do tratamento da laminite (Peroni, 2009) e são capazes de induzir a apoptose em tecidos tumorais (Elder e Paraskeva, 1999; Brown et al., 2001). A indução da apoptose é desejável na regressão de células tumorais (Brown et al., 2001; Elder e Paraskeva, 1999), porém uma elevada ocorrência de apoptose torna-se prejudicial e está implicada em lesões degenerativas neurológicas (Tripathy e Grammas, 2009) artrose (Yoon et al., 2003) e laminite, tendo sido descrita em tecido lamelar de cavalos com laminite aguda adquirida naturalmente (Faleiros et al., 2004). Laskoski et al. (2010) não observaram diferenças nas taxas de apoptose entre animais tratados com hidrocortisona e animais do grupo controle. Porém, o efeito dos AINEs sobre a apoptose em tecido lamelar ainda não é conhecido.

O objetivo deste trabalho foi avaliar o efeito de diferentes anti-inflamatórios administrados em equinos após a indução experimental da laminite por sobrecarga de carboidratos, sobre o índice apoptótico no tecido lamelar nos diferentes grupos testados.

\section{MATERIAL E MÉTODOS}

No presente estudo, foram utilizados materiais de biópsia colhidos previamente durante o experimento de indução de laminite (Paes Leme, 2004). As amostras foram obtidas de 20 equinos hígidos, sem raça definida, machos castrados, com idade entre três e 15 anos e escore corporal entre dois (moderado) e três (bom), segundo Speirs (1997), peso vivo entre 264 e 344kg e sem sinais clínicos e radiológicos de laminite.

Após jejum alimentar e hídrico de 12 horas, foi feita a sobrecarga pela administração de $20 \mathrm{~g} / \mathrm{kg}$ de peso corporal de amido de milho (Milhena, Nutril, Brasil), diluídos em água e administrados por sonda nasogástrica.

Os animais foram divididos aleatoriamente em quatro grupos experimentais, cada qual com cinco animais. Após 36 horas da administração do amido, cada grupo recebeu, por via intravenosa, um dos quatro diferentes tratamentos: o grupo controle recebeu solução salina $(10 \mathrm{~mL})$, os demais receberam um dos seguintes anti-inflamatórios: cetoprofeno (Ketofen, Merial, Brasil) $(2,2 \mathrm{mg} / \mathrm{kg})$, fenilbutazona (Equipalazone Marcolab, Brasil) (4,4mg/kg) e flunixin meglumina (Flumegan - Marcolab, Brasil) $(1,1 \mathrm{mg} / \mathrm{kg})$. As doses utilizadas seguiram a recomendação usual para a espécie, conforme Plumb (2011), e foram repetidas a cada 12 horas até 72 horas após a sobrecarga, quando, então, foram feitas as biópsias.

Para realização das biópsias, os animais, após jejum alimentar de 12 horas, foram sedados com uma associação de acepromazina 1\% (Acepran Univet, Brasil) e romifidina $1 \%$ (Sedivet Boehringer Ingelheim Vetmedica, Brasil), nas doses de $0,05 \mathrm{mg} / \mathrm{kg}$ e $100 \mathrm{mcg} / \mathrm{kg}$, 
respectivamente. O local de biópsia escolhido foi o terço médio da face dorsal da região dorsal da muralha dos cascos dos membros torácicos. Para tanto, os cascos foram previamente adelgaçados com grosa e rineta até que a camada interna flexível e avascular fosse alcançada. As biópsias foram feitas após bloqueio anestésico perineural nos nervos palmares lateral e medial, com lidocaína 2\% (Lidocaína - Hipolabor, Brasil) sem vasoconstritor. $\mathrm{O}$ material foi coletado utilizando-se um punch de biópsia de $1,0 \mathrm{~cm}$ de diâmetro na extremidade cortante, posicionado perpendicularmente sobre a superfície previamente adelgaçada na face dorsal da muralha e fazendo-se movimentos rotativos e basculares discretos. Procurou-se coletar as amostras na mesma localização em todos os equinos. Após a coleta, as amostras foram acondicionadas em frascos contendo formol tamponado a $10 \%$, por 24 horas, quando, então, o formol foi substituído e o material armazenado até o processamento no laboratório de histopatologia.

Para a utilização da técnica de TUNEL, o material histológico foi cortado com $6.0 \mu \mathrm{m}$ de espessura, fixado em lâminas carregadas

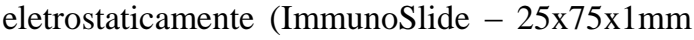
EasyPath - Erviegas, Brasil) no dia anterior, ficando incubado em estufa a $37^{\circ} \mathrm{C}$ com atmosfera controlada $\left(\mathrm{CO}_{2}, 9 \%\right)$ por 12 horas até o processamento. A técnica empregada para coloração foi a de TUNEL, utilizando-se o kit de detecção (TdT- FragEL ${ }^{\mathrm{TM}}$ DNA Fragmentation Detection kit, Calbiochem, USA). Ao protocolo prescrito pelo fabricante, foi adicionado triton $0,5 \%$, associado à proteinase $\mathrm{K}$ fornecida no kit, para intensificar a permeabilização da membrana celular aos reagentes (Faleiros et al., 2004), facilitando que a coloração se concentrasse no núcleo (Labat-Moleur et al., 1998). Durante o processamento, os cortes foram desparafinizados por imersão em xileno à temperatura ambiente e, posteriormente, hidratados em banhos sucessivos com concentrações decrescentes de etanol, iniciando com etanol absoluto (100\%), seguido de banhos com concentrações de etanol a 90, 80 e 70\%, respectivamente, e terminando com lavagem em 1X TBS. Após essa etapa, foram instilados sobre cada amostra histológica $30 \mu \mathrm{lde}$ triton a $0,5 \%$, incubando-se as lâminas por 10 minutos à temperatura ambiente em câmara úmida. Em seguida, foi utilizada a proteinase $\mathrm{K}$ (1:100) diluída em Tris (temperatura ambiente,
10 minutos). As lâminas foram lavadas em 1x TBS, e a inativação da peroxidase endógena foi obtida incubando-se as lâminas com peróxido de hidrogênio a $3 \%$ por cinco minutos. A reação de equilíbrio foi obtida com a aplicação de $100 \mu \mathrm{L}$ por lâmina de solução tampão fornecida pelo fabricante (temperatura ambiente por 10 a 30 minutos). A reação de marcação foi feita incubando-se as lâminas com a enzima TdT $\left(37^{\circ} \mathrm{C}\right.$, em câmara úmida, por 1,5 hora). A reação foi interrompida por solução tampão. A reação de detecção foi feita com o anticorpo conjugado, incubando-se as lâminas em câmara úmida por 30 minutos. Após o período de incubação, as lâminas foram lavadas em 1x TBS e utilizou-se a DAB (diaminobenzidina associada ao peróxido de hidrogênio) incubada por cinco minutos em temperatura ambiente para identificação das células marcadas. Em seguida, utilizou-se o verde de metila como contracoloração e as lâminas foram montadas.

Os cortes histológicos foram digitalizados, e as imagens capturadas em um microscópio óptico de luz comum (Olympus-CH30, Japão), utilizando-se objetiva de 40x com uma câmera digital (JVC Digital Color Video Camera - TKC720U, Japão) de captura de imagens acoplada. Capturaram-se 12 campos por lâmina, sendo quatro campos no ápice, quatro no corpo e quatro na base, usando-se como referência as lâminas epidermais primárias. Segundo cálculo prévio do índice de dispersão, este número foi considerado como tendo uma segurança de $50 \%$ em relação à contagem de oito campos.

A contagem das células marcadas foi feita manualmente, utilizando-se um programa de processamento e análise de imagens (IMAGE J versão $1.39 \mathrm{u}$ - Rasband, W.S., U.S. National Institutes of Health, Bethesda, Maryland, USA). O índice apoptótico foi calculado dividindo-se o número de células apoptóticas pelo número de células totais (Faleiros et al., 2004). A morfologia celular foi usada como método complementar para diferenciar células com alterações morfológicas compatíveis com apoptose de células com morfologia normal.

Somente foram contadas células epidermais basais (stratum basale), células supra-basais (stratum spinosum) e queratinócitos localizados ao longo do eixo queratinizado das lâminas epidermais primárias. 
As extremidades laterais dos cortes, considerando-se que a zona queratinizada (stratum medium) e a derme profunda são as regiões externas e internas, respectivamente, foram desprezadas das contagens, pois sempre apresentavam células marcadas intensamente. Também foram desprezadas outras áreas que apresentassem um padrão de marcação muito uniforme.

Os parâmetros utilizados para identificação de uma célula em apoptose foram: a presença de núcleo pequeno, redondo e intensamente corado, e a formação de alo de anoiquia, conforme parâmetros utilizados no laboratório de apoptose da UFMG (Mendes et al., 2009; Alves et al., 2011). Células ovais, fracamente coradas e com um pequeno acúmulo de heterocromatina, foram consideradas normais. Células basais e suprabasais normais foram contadas juntas. Queratinócitos foram contados separados. Células basais e suprabasais apresentando características morfológicas de necrose foram contadas juntas. Queratinócitos com morfologia de necrose foram contados separados.

Os índices de apoptose no tecido laminar, determinado pelo percentual de células apoptóticas em relação ao total de células avaliadas, foram comparados estatisticamente pelo método de Kruskal-Wallis e pelo teste de Dunn a 5\% para comparações múltiplas pareadas. Na determinação do índice apoptótico por campo microscópico, foi empregado o teste de análise de variância para um fator, seguido pelo teste de Tukey a $5 \%$.

\section{RESULTADOS}

Em todos os cortes histológicos pela técnica de TUNEL, observou-se maior quantidade de células epiteliais intensamente marcadas, com uma coloração marrom-escura nas extremidades laterais. Uma possível explicação para essa diferença na marcação das extremidades pode ser devido ao trauma tecidual ocasionado pelo punch de biópsia durante a coleta. O mesmo fato ocorreu nos campos onde não havia derme profunda, camada entre as lâminas epidermais primárias e a falange distal e nas células epiteliais basais localizadas na região da base das lâminas epidermais primárias quando as lâminas dermais primárias e secundárias estavam ausentes. Essas células apresentavam-se coradas mais intensamente e com núcleos picnóticos em relação a células do corpo das lâminas epidermais primárias, onde havia a presença das lâminas dermais. Essas áreas foram desprezadas na captura das imagens por se entender que se tratavam de artefato do método de biópsia. Os cortes histológicos apresentaram variações no padrão de coloração (marcação). Variações de colorações entre fragmentos cortados do mesmo bloco, fixados na mesma lâmina e corados ao mesmo tempo com o mesmo protocolo, foram comuns. Um corte poderia estar fracamente marcado, enquanto o outro poderia apresentar um padrão de marcação das células mais intenso.

As médias e desvios-padrão para os índices apoptóticos de células lamelares basais obtidos dos grupos tratados com cetoprofeno, fenilbutazona, e flunixin meglumine e do grupo controle foram, respectivamente, 55 \pm 10 , $52,6 \pm 16,54,6 \pm 19$ e $58,2 \pm 17$ (Fig. 1a). Não foram observadas diferenças significativas entre os grupos $(\mathrm{P}=0,959)$.

As médias dos índices apoptóticos de queratinócitos para os grupos tratados com cetoprofeno, fenilbutazona, e flunixin meglumina e para o grupo controle foram, respectivamente, $60,2 \pm 0,13,68,8 \pm 0,20,68,2 \pm 0,23$ e $64,4 \pm 0,20$. As médias dos índices de necrose nesses mesmos grupos foram $0,003 \pm 0,003 ; 0,0068 \pm 0,007$; $0,0028 \pm 0,003 ; 0,0038 \pm 0,001$, respectivamente. Não houve diferença significativa entre os grupos $(\mathrm{P}=0,731)$ (Fig. 1b,c).

Células com morfologia normal se apresentaram fracamente coradas de marrom-claro, enquanto células apoptópticas apresentaram coloração marrom-escura intensa, quase negra (Fig. 2). 


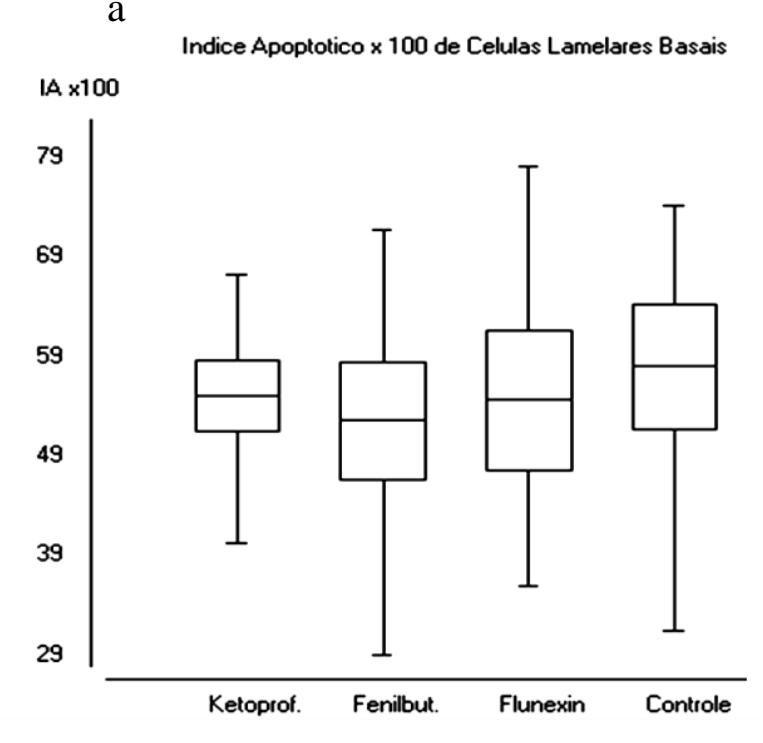

b

IAQ $\times 100 \quad$ Indice Apoptotico $\times 100$ de Queratinocitos

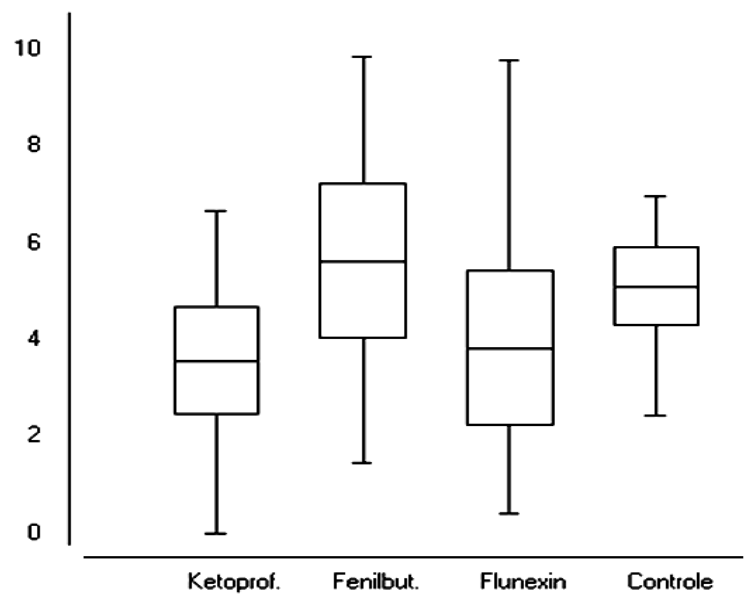

c

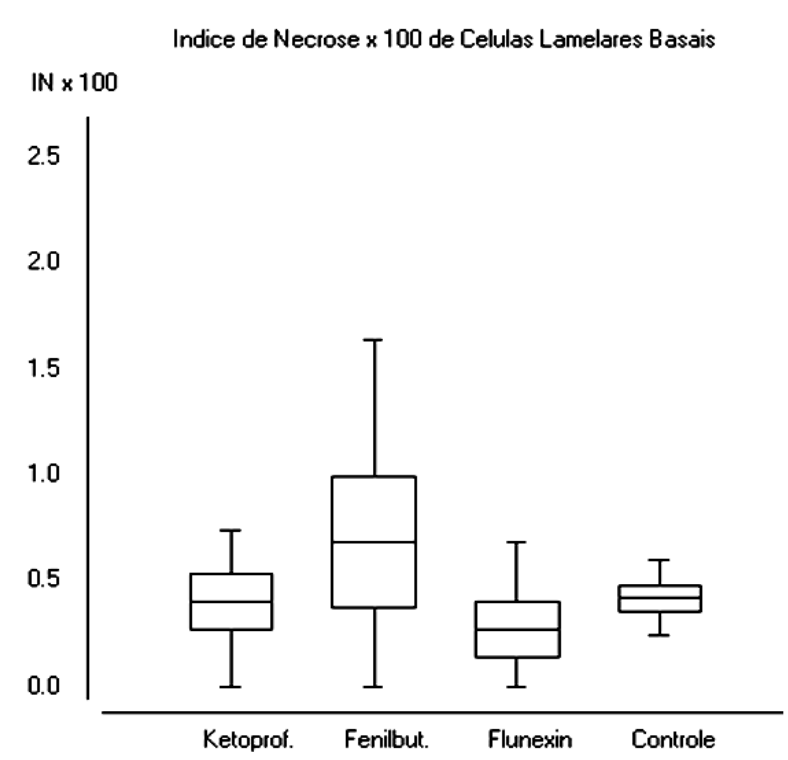

Figura 1. Médias e erros-padrão dos índices apoptóticos de células lamelares basais e suprabasais (a), de queratinócitos (b) e de índices de necrose de células lamelares basais e suprabasais (c) de cascos de equinos com laminite em fase aguda. Verificam-se três grupos tratados com os anti-inflamatórios não esteroidais cetoprofeno, fenilbutazona, flunixin meglumina e o grupo controle $(\mathrm{P}>0,05)$. 


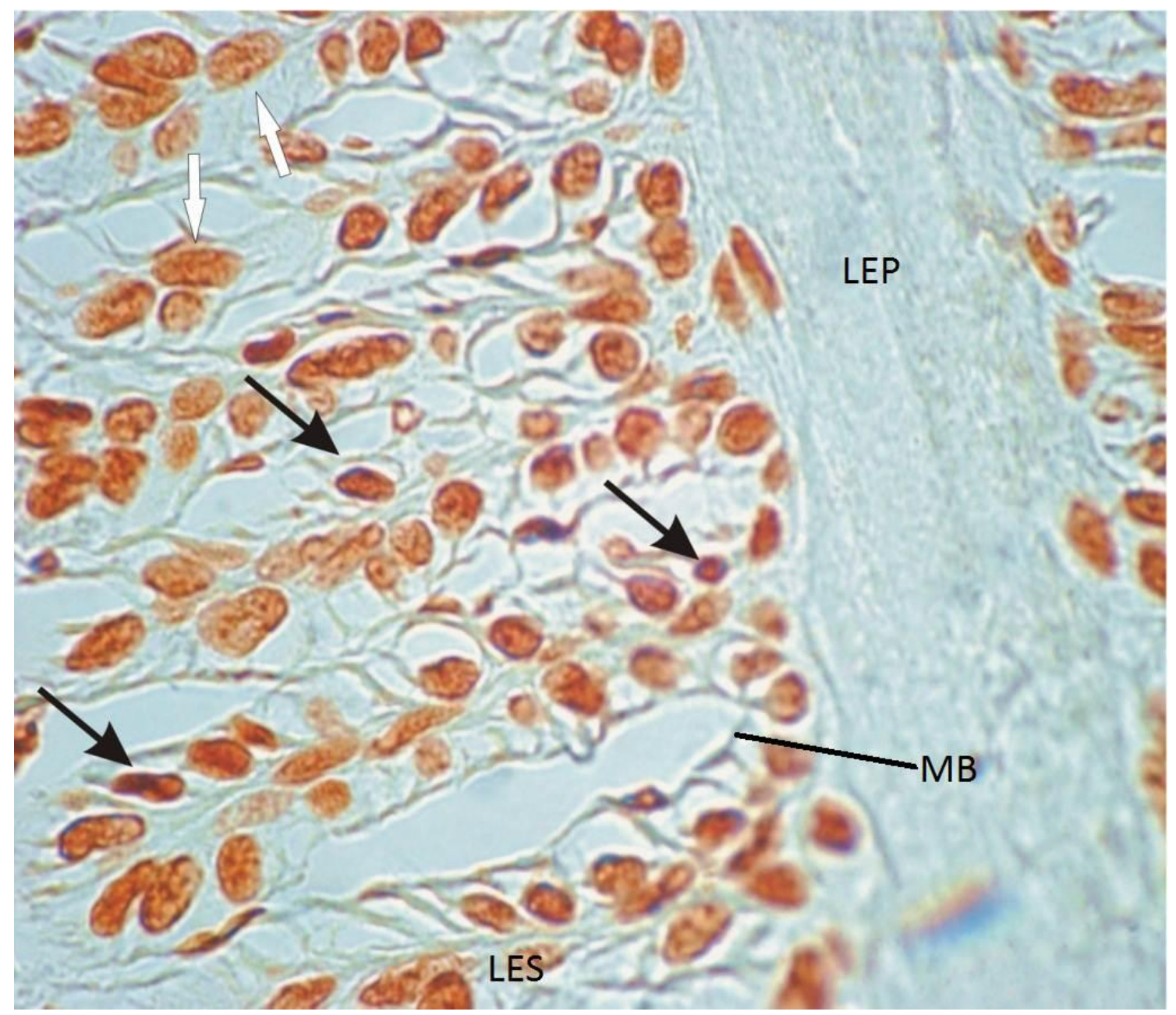

Figura 2. Fotomicrografia do tecido lamelar de equinos com laminite em fase aguda, marcado pela técnica de TUNEL, mostrando parte da lâmina epidermal primária (LEP), lâminas epidermais secundárias (LES), membrana basal (MB). Células com morfologia de apoptose com coloração marrom-escura, diminuição do volume celular e anoiquia (setas negras), células com morfologia normal e coloração marrom-clara (setas brancas). Contracoloração com verde de metila, objetiva de 40x.

\section{DISCUSSÃO}

Células que estavam em diferentes estágios de morte celular apresentaram diferentes tonalidades de cor marrom. A diferenciação entre uma célula normal e uma célula em estágio inicial de morte celular foi feita pelas alterações morfológicas típicas da apoptose já descritas anteriormente (Fig. 2). A técnica de TUNEL permitiu a identificação das alterações morfológicas celulares compatíveis com a apoptose que são vistas nas lâminas coradas com hematoxilina e eosina e facilitou a identificação de células em apoptose. As variações no padrão de coloração apresentado foram observadas em outros tecidos corados pela técnica de TUNEL e encontram-se citadas na literatura como uma dificuldade esperada na padronização da técnica (Labat-Moleur et al., 1998; Vasconcelos, 2008). Limitações de sensibilidade e especificidade já foram descritas, sendo a falta de padronização no processo de fixação em tecidos arquivados $o$ principal fator para a baixa especificidade por vezes apresentada (Labat-Moleur et al., 1998). Apesar disso, essas dificuldades não impediram a execução de uma avaliação quantitativa da apoptose, uma vez que se utilizou, além da marcação positiva do TUNEL, o critério morfológico para a classificação das células 
apoptóticas como proposto nos trabalhos de Mendes et al. (2009) e Alves et al. (2011).

Os animais deste experimento apresentaram sinais clínicos de endotoxemia por 12 a 24 horas antes de começarem a ser medicados (Paes Leme, 2004). Citocinas pró-inflamatórias e interleucinas são sintetizadas rapidamente após exposição de fagócitos mononucleares e neutrófilos às endotoxinas, produzindo migração de leucócitos e ativação endotelial no tecido lamelar (Belknap, 2009). Consegue-se atenuar os efeitos da endotoxemia quando os antiinflamatórios são administrados antes de uma dose subletal de endotoxinas (Moore et al., 1986).

No presente trabalho, as biópsias foram feitas após 72 horas da administração de carboidratos. Entre 12 e 36 horas após a administração do amido, $75 \%$ dos cavalos já apresentavam claudicação; com 72 horas, todos já estavam na fase aguda da laminite (Paes Leme, 2004). A instauração do quadro de laminite foi mais rápida nos animais deste estudo que o observado por Van Eps et al. (2004), que relataram que a fase prodrômica da laminite ocorre entre 20 e 72 horas após a ingestão excessiva de carboidratos, com uma média de 40 horas. Ainda durante a fase prodrômica, a lesão da membrana basal é a primeira lesão histopatológica encontrada e também a mais significativa, estando presente muito antes do aparecimento dos primeiros sinais clínicos da laminite (Croser e Pollit, 2006), iniciando-se, portanto, antes do momento da realização das biópsias neste estudo. No modelo de indução de laminite por oligofrutose, alterações histológicas já são detectadas com 12 horas após a sobrecarga com oligofrutose (Croser e Pollitt, 2006) e com 48 horas após a sobrecarga de carboidratos (Sampaio et al., 2004).

Neste estudo, a ausência de diferenças significativas entre os grupos de animais tratados em relação ao grupo controle não permitiu identificar se o uso de anti-inflamatórios poderia induzir apoptose, se realmente são indiferentes ou se seriam capazes de reduzir a apoptose. Porém, algumas hipóteses podem ser consideradas.

Primeiramente, os tratamentos com antiinflamatórios iniciaram-se após 36 horas da sobrecarga de carboidratos. Além disso, os animais receberam apenas três doses de antiinflamatórios entre o início do tratamento e a biópsia (Paes Leme, 2004), em contraposição a outro estudo, quando os animais receberam altas doses em 24 horas (Blikslager, 2009). Quando começaram a ser medicados, as alterações histológicas provavelmente já estavam ocorrendo em, ao menos, $75 \%$ dos cavalos, e a administração dos anti-inflamatórios não foi capaz de influenciar significativamente no índice apoptótico, seja aumentando ou reduzindo, como também não foi capaz de evitar as alterações histológicas citadas no estudo de Paes Leme (2004), quando 90\% dos cavalos apresentaram lesões histológicas de moderada a extensa, segundo classificação histológica de Pollitt (1996).

Em estudo que avaliou cavalos com casos naturais de laminite com duração igual ou maior que uma semana e os comparou com animais com até uma semana de desenvolvimento da doença, Faleiros et al. (2004) observaram índices apoptóticos maiores nos cavalos com laminite aguda (até uma semana). Posteriormente, compararam esses resultados com casos de laminite induzida por dois protocolos, extrato de nogueira preta e sobrecarga por carboidratos com até 18 horas de indução. Somente os animais com laminite aguda natural diferiram estatisticamente do grupo controle (sem laminite). A hipótese proposta por Faleiros et al. (2004) para a baixa incidência de apoptose em animais com laminite induzida por sobrecarga de carboidratos ou extrato de nogueira preta foi $o$ curto espaço de tempo entre a sobrecarga e o sacrifício dos animais, cerca de 10 a 18 horas, tempo considerado curto para que se complete o processo apoptótico em células epidérmicas (Teraki e Shiohara, 1999). E os baixos índices observados nos animais com laminite natural poderiam ser decorrentes do uso de antiinflamatórios, base do tratamento em casos de laminite.

O processo inflamatório induz apoptose em células epiteliais humanas pela ação do TNF- $\alpha$ (Banno et al., 2004) na via extrínseca da apoptose (Jeong e Seol, 2008). É crível supor que um processo inflamatório no tecido lamelar (Belknap, 2009) também poderia induzir o aumento no índice apoptótico no mesmo tecido. 
Outra consideração a ser feita é com relação aos grupos controle. No trabalho de Faleiros et al. (2004), demonstrou-se a elevação dos índices de apoptose em animais com laminite aguda, em comparação com o controle negativo, animais sem laminite. No presente trabalho, não houve diferenças significativas entre os diferentes grupos, porém foram utilizados apenas controle positivo e grupos tratados com antiinflamatórios, ou seja, a laminite foi induzida em todos os grupos, uma vez que o objetivo do trabalho foi avaliar se os AINEs poderiam influir nos índices apoptóticos de equinos com laminite, fato não observado no período estudado.

Os efeitos dos AINEs sobre diferentes tipos celulares são conflitantes, podendo induzir a apoptose em alguns estudos (Brown et al., 2001; Elder e Paraskeva, 1999), inibi-la em outros, por exemplo, ao inibir a liberação de citocinas e quimiocinas (Tripathy e Grammas, 2009), pela inibição direta da caspase-3 e de outras moléculas pró-apoptóticas (Yoon et al., 2003). Entretanto, outros estudos também verificaram que esses fármacos podem não afetar o índice apoptótico, como verificado após o uso da fenilbutazona em cultura de fibroblastos de embriões de galinha (Lu et al., 1995) e pelo uso de hidrocortisona em tecido lamelar de cavalos (Laskoski et al., 2010), porém os autores só avaliaram os animais até 18 horas, cabendo o mesmo comentário referente ao trabalho de Faleiros et al. (2004). A inibição da apoptose no tecido lamelar poderia ocorrer tanto pela inibição da produção de citocinas e quimiocinas (Tripathy e Grammas, 2009) quanto pela ação direta na cascata apoptótica (Yoon et al., 2003) ou por algum outro mecanismo. No trabalho de Yoon et al. (2003), o bloqueio do mecanismo apoptótico foi obtido pelo pré-tratamento do tecido com anti-inflamatórios, o que dá suporte ao conceito de tratamento preventivo para animais sob risco de desenvolvimento da laminite (Stashak, 2002).

Em relação ao tecido lamelar, uma incidência maior de apoptose poderia estar implicada no aumento das lesões. A lâmina epidermal secundária possui uma única camada de células epidermais basais na borda externa (Leach e Oliphant, 1983) que estão fixadas na membrana basal (Pollit, 1996). O aumento da incidência de apoptose nessa camada de células poderia provocar um maior destacamento da membrana basal e, consequentemente, o afastamento das lâminas epidermais e dermais, produzindo maiores danos ao tecido. O aumento da necrose poderia também ser uma das consequências, já que frequentemente a necrose é precedida pela apoptose (Zhivotovsky, 2004).

A administração de anti-inflamatórios após o início da manqueira (Paes Leme, 2004) se aproxima bastante da realidade que acontece na rotina clínica, em que os proprietários só reconhecem o problema quando os animais com laminite atingem o grau três de manqueira, segundo a escala de Obel (Baxter, 1992). Assim, estudos posteriores, em que os AINEs pudessem ser aplicados em diferentes momentos do processo de laminite, poderiam esclarecer muitas das questões que se colocam no momento.

\section{CONCLUSÃO}

Os anti-inflamatórios cetoprofeno, fenilbutazona e flunixin meglumine, quando administrados 36 horas após a indução de laminite por sobrecarga de amido, não alteram significativamente os índices apoptóticos ou de necrose de células epidermais lamelares quando comparados ao grupo controle não tratado. Outros estudos, com diferentes períodos de avaliação, são necessários para esclarecer os efeitos dos anti-inflamatórios não esteroidais na fisiopatologia da laminite em equinos, especialmente no que concerne à participação da apoptose.

Comitê de ética e biossegurança: Protocolo de aprovação Cetea/UFMG: nº 137/2008.

\section{REFERÊNCIAS}

ALVES, G.E.S.; MENDES, H.M.F.; ALVES, T.G.S. et al. Hydrocortisone decreases apoptosis in jejunum of horses subjected to experimental ischemia and reperfusion. Pesq. Vet. Bras., v.31, p.471-476, 2011.

BANNO, T.; GAZEL, A.E.; BLUMENBERG, M. Effects of tumor necrosis factor- $\alpha$ (tnf- $\alpha$ ) in epidermal keratinocytes revealed using global transcriptional profiling. The J. Biol. Chem., v.279, p.32633-32642, 2004.

BAXTER, G.M. Laminitis. In: Current therapy in equine medicine. 3.ed. Philadelphia: W.B.Saunders Company, 1992. p.154-160. 
BELKNAP, J.K. Phatogenesis of laminitis. In: In: ROBINSON, N.E.; SPRAYBERRY, K.A. (Eds), Current therapy in equine medicine. 6. ed. Saint Louis: Saunders Elsevier, 2009. p.541-542.

BLACK, S.J.; LUNN, D.P.; YIN, C. et al. Leukocyte emigration in the early stages of laminitis. Vet. Immunol. Immunophatol., v.109, p.161-166, 2006.

BLIKSLAGER, A.T. Nonsteroidal antiinflamatory drugs. In: Current Therapy in Equine Medicine. 6.ed. Saint Louis: Saunders Elsevier, 2009. p.7-9.

BROWN, W.A. Non-steroidal anti-inflammatory drugs with activity against either cyclooxygenase 1 or cyclooxygenase 2 inhibit colorectal cancer in a DMH rodent model by inducing apoptosis and inhibiting cell proliferation. Gut, v.48, p.660666, 2001.

COLLINS, M.K.L.; PERKINS, G.R.; RODRIGUEZTARDUCHY, G. et al. Growth factors as survival factors: regulation of apoptosis. BioEssays, v.16, p.133-138, 1994.

COLUMBANO, A. Cell death: current difficulties in discriminating apoptosis from necrosis in the context of pathological processes in vivo. J. Cell. Bioch., v.58, p.81-190, 1995.

CROSER, E.L.; POLLITT, C.C. Acute laminitis: descriptive evaluation of serial hoof biopsies. In: Proceedings. AAEP, v.52, p.542-546, 2006.

ELDER D.J.E.; PARASKEVA, C. Induced apoptosis in the prevention of colorectal cancer by non-steroidal anti-inflammatory drugs. Apoptosis, v.4, p.365-372, 1999.

FALEIROS, R.R.; STOKES, A.M.; EADES, S.C. et al. Assessment of apoptosis in epidermal lamellar cells in clinically normal horses and those with laminitis. Am. J. Vet. Res., v.65, p.578$585,2004$.

JEONG, S.Y.; SEOL, D.W. The role of mitochondria in apoptosis. BMB Reports, v.41, p.11-22, 2008.

KERR, J.F.; WYLLIE, A.H.; CURRIE, A.R. Apoptosis: a basic biological phenomenon with wide-ranging implications in tissue kinetics. $\mathrm{Br}$. J. Cancer, v.6, p.239-57, 1972.
LABAT-MOLEUR, F.; GUILLERMET, C.; LORIMIER, P. et al. TUNEL apoptotic cell detection in tissue sections: critical evaluation and improvement. J. Hist. Cytoch., v.46, p.327334, 1998.

LASKOSKI, L.M. et al. Morphological abnormalities and apoptosis in lamellar tissue of equines after intestinal obstruction and treatment with hydrocortisone. Arq. Bras. Med. Vet. Zootec., v.62, p.1331-1339, 2010.

LEACH, D.H.; OLIPHANT, L.W. Ultrastructure of the equine hoof wall secondary epidermal lamellae. Am. J. Vet. Res., v.44, p.1561-1570, 1983.

LU, X.; XIE, W.; REED, D. et al. Nonsteroidal antiinflammatory drugs cause apoptosis and induce cyclooxygenases in chicken embryo fibroblasts. In: Proceedings. Nat. Acad. Sci., v.92, p.7961-7965, 1995.

MATUTE-BELLO, G.; MARTIN, T.R. Review: Apoptosis in acute lung injury. Critical Care, v.7, p.355-358, 2003.

MENDES, H.M.F.; FALEIROS, R.R.: VASCONCELOS, A.C. et al. Apoptose no cólon menor equino submetido à isquemia e reperfusão experimentais. Pesq. Vet. Bras., v.29, p.198-204, 2009.

MOORE, J.N.; HARDEE, M.M.; HARDEE, G.E. Modulation of arachidonic acid metabolism in endotoxic horses: Comparison of flunixin meglumine, phenylbutazone, and a selective thromboxane synthetase inhibitor. Am. J. Vet. Res., v.47, p.110-113, 1986.

PAES LEME, F.O. Efeito da fenilbutazona, cetoprofeno e meglumina sobre plaquetas de equinos hígidos - in vitro - e com laminite experimental - in vivo - estudada clínica, radiológica e laboratorialmente. 2004. $136 f$. Tese (Doutorado em Ciência Animal) - Escola de Veterinária da Universidade Federal de Minas Gerais, Belo Horizonte, MG.

PERONI, J.F. Pharmacologic Management of Laminitis. In: ROBINSON, N.E. and SPRAYBERRY, K.A. (Eds). Current Therapy in Equine Medicine. 6.ed. Sth Louis :Saunders Elsevier, 2009. p.543-546.

PLUMB, D.C. Plumb's Veterinary Drug Handbook: Pocket. 7.ed. Stockholm, Wisconsin :Wiley-Blackwell. 2011.1584p. 


\section{Gonçalves et al.}

POLLITT, C.C. Basement membrane pathology: a feature of acute equine laminitis. Equine. Vet. J., v.28, p.38-46, 1996.

POLLITT, C.C.; DARADKA, M. Equine laminitis basement membrane pathology: loss of type IV collagen, type VII collagen and laminin immunostaining. Equine Vet. J., v.26, p.139-144, 1998.

RENEHAN, A.G.; BOOTH, C.; POTEN, C.S. What is apoptosis, and why is it important? BMJ, v.322. p.1536-1538, 2001.

SAMPAIO, L.R.C.; CANOLA, J.C.; LACERDA NETO, J.C.; De MORAES, E.J.R. Histologic alterations of the basement membrane of the dermal and epidermal layers of the hoof in horses with acute laminitis. Int. J. Morphol., v.4, p.307312,2004

SPEIRS, V.C. The alimentary tract. In: Clinical examination of horses. Philadelphia: Saunders, 1997. p.261-298

SOUZA, A.H. Aspectos clínico, fisiopatológico e terapêutico na laminite experimental em equinos. 2007. 219f. Tese (Doutorado em Cirurgia Veterinária) - Faculdade de Ciências Agrárias e Veterinárias, Universidade Estadual Paulista, Jaboticabal.
STASHAK, T.S. Lameness, The Foot. In: Adams's Lameness in Horses. 5.ed. Philadelphia: Lippincott Williams and Wilkins, 2002. p.645664.

TERAKI, Y.; SHIOHARA, T. Apoptosis and the skin. Eur. J. Dermatol., v.9, p.413-426, 1999.

TRIPATHY, D.; GRAMMAS, P. Acetominophen inhibitis neuronal inflammation and protects neurons from oxidative stress. $J$. Neuroinflammat., v.6, p.1-10, 2009.

Van EPS, A.W.; WALTERS, L.J.; BALDWIN, G.I. et al. Distal limb cryotherapy for the prevention of acute laminitis. Clin. Techn. Equine Pract., v.3, p.64-70, 2004.

YOON, J.B.; KIM, S.J.; HWANG, S.G. et al. Non-steroidal anti-inflammatory drugs (NSAIDs) inhibit nitric oxide -induced apoptosis and dedifferentiation of articular chondrocytes independent of cyclooxygenase activity. J. Biol. Chem., v.278, p.15319-15325, 2003.

ZHANG, X.; CHEN, Y.; JENKINS, L.W. et al. Bench-to-bedside review: Apoptosis/ programmed cell death triggered by traumatic brain injury. Critical Care. v.9, p.66-75, 2005.

ZHIVOTOVSKY, B. Apoptosis, necrosis and between. Cell Cycle, v.3, p.64-66, 2004. 